\title{
The effect of the GENTLE/s robot- mediated therapy system on arm function after stroke
}

Article

Accepted Version

Coote, S., Murphy, B., Harwin, W. and Stokes, E. (2008) The effect of the GENTLE/s robot-mediated therapy system on arm function after stroke. Clinical Rehabilitation, 22 (5). pp. 395405. ISSN 0269-2155 doi:

https://doi.org/10.1177/0269215507085060 Available at https://centaur.reading.ac.uk/15188/

It is advisable to refer to the publisher's version if you intend to cite from the work. See Guidance on citing.

To link to this article DOI: http://dx.doi.org/10.1177/0269215507085060

All outputs in CentAUR are protected by Intellectual Property Rights law, including copyright law. Copyright and IPR is retained by the creators or other copyright holders. Terms and conditions for use of this material are defined in the End User Agreement.

www.reading.ac.uk/centaur 
Central Archive at the University of Reading

Reading's research outputs online 


\title{
The effect of the GENTLE/s robot-mediated therapy system on arm function after stroke
}

\author{
Susan Coote, Brendan Murphy, William Harwin, and Emma Stokes ${ }^{1}$
}

\section{Abstract}

Objective: To evaluate the effect of robot-mediated therapy on arm dysfunction post stroke.

Design: A series of single-case studies using a randomized multiple baseline design with $A B C$ or ACB order. Subjects $(n=20)$ had a baseline length of 8,9 or 10 data points. They continued measurement during the B -- robot-mediated therapy and C -sling suspension phases.

Setting: Physiotherapy department, teaching hospital.

Subjects: Twenty subjects with varying degrees of motor and sensory deficit completed the study. Subjects attended three times a week, with each phase lasting three weeks.

Interventions: In the robot-mediated therapy phase they practised three functional exercises with haptic and visual feedback from the system. In the sling suspension phase they practised three single-plane exercises. Each treatment phase was three weeks long.

Main measures: The range of active shoulder flexion, the Fugl-Meyer motor assessment and the Motor Assessment Scale were measured at each visit.

Results: Each subject had a varied response to the measurement and intervention phases. The rate of recovery was greater during the robot-mediated therapy phase than in the baseline phase for the majority of subjects. The rate of recovery during the robot-mediated therapy phase was also greater than that during the sling suspension phase for most subjects.

Conclusion: The positive treatment effect for both groups suggests that robotmediated therapy can have a treatment effect greater than the same duration of nonfunctional exercises. Further studies investigating the optimal duration of treatment in the form of a randomized controlled trial are warranted.

\section{Introduction}

In stroke, residual deficits in the function of the hand and arm are common; this functional difficulty is recognised as contributing to poor quality of life and decreased well-being. ${ }^{1}$ It is also recognised that for optimal cortical re-organisation to occur post stroke, there is a requirement for high levels of repetition of tasks and exercises that are both challenging and engaging. ${ }^{2-4}$ Nonetheless, it has been suggested that the dose of physiotherapy intervention that occurs post stroke is, at best, "homeopathic" ${ }^{5}$ and that the arm receives significantly less attention that the lower limb. ${ }^{6}$ There is some evidence to suggest that if the duration or intensity of intervention for the arm is increased sufficiently, it will lead to an improved outcome of motor impairment in the affected arm. ${ }^{7,8}$ Attention is now focusing on novel technologies that can enable individuals to complete repetitious exercise programmes to supplement the traditional 'hands-on', labour intensive physiotherapy. One way of delivering more intervention without the need for more therapists is by using robotic technology. The results of

${ }^{1}$ Published in Clin Rehabil May 2008 22: 395-405, doi:10.1177/0269215507085060 
four robotic systems have been published in the clinical literature to date. In the United States the MIME, ${ }^{9-13}$ MIT-Manus ${ }^{14-24}$ and the ARM-Guide ${ }^{25-27}$ systems have demonstrated results that suggest the delivery of exercise intervention using robotic devices can have positive effects on range of motion, strength, and motor activity. Functional improvement has been 'inconsistently reported' and minimal. ${ }^{20,28,29}$

In Europe, three systems have been developed for arm exercises post stroke- the Reharob $^{30}$, Bi-Manu-Track ${ }^{31}$, and GENTLE/s ${ }^{32}$ systems. With respect to the latter system, the results of a single case study suggesting a positive treatment effect have been published. ${ }^{33}$ The aim of this paper is to present results from the cohort of 20 subjects.

\section{Methods}

\subsection{Design}

A series of single case studies, using randomised multiple baseline design, with randomised treatment phases $(\mathrm{ABC}$ or $\mathrm{ACB})$ was applied. Subjects were randomly allocated by choosing a sealed envelope from two selections containing the possible length of baseline and the possible treatment orders. In the 'A' or 'baseline' phase, all subjects were measured three times per week, yielding 8,9 or 10 data points. During the 'B' or RMT phase, measurement continued three times per week and in addition the subjects received the RMT treatment. The ' $\mathrm{C}$ ' or SS phase was employed as a control phase, to observe the effect of a similar dosage of intervention, which also involved repetitious movement, with ongoing trice weekly measurement.

\subsection{Participants}

Twenty subjects were included in the study. All had residual arm dysfunction following a first episode of stroke. To be included they had to be able to provide informed consent and have sufficient communication abilities to complete the outcome measures and treatment procedures (this was assessed by their speech and language therapist). They were excluded if they had a pacemaker (due to possible electromagnetic field interference of the system). A sample of convenience was employed and senior physiotherapists working in stroke rehabilitation in 3 academic teaching hospitals in Dublin knowledgeable of the inclusion criteria and trial methodology suggested names of potential participants who had attended their physiotherapy service. They were then assessed for their suitability (Short Orientation Memory Concentration Test ${ }^{34}$ score greater than 20, residual arm deficit), presented with an information leaflet and following informed consent were recruited to the study. The study protocol was approved by the local ethics committee.

\subsection{Intervention}

The RMT system comprises a three-degree of freedom haptic interface arm (Haptic Master, Fokker Control Systems) with a wrist attachment mechanism, two embedded computers, a monitor and speakers, seating for the subject and an overhead arm support system. Treatment with the RMT system involved the subject being seated at the workstation. The affected arm was de-weighted through a free moving elbow splint attached to the overhead frame; this was to remove the effect of gravity 
and minimise any subluxation present. Support for the trunk was provided by a seat harness/jacket which also provided a physical prompt when compensatory trunk movements were used. The subject was connected to the system by a wrist splint that held their wrist in $15^{0}$ extension, which was in turn connected to a magnetic safety connection that prevented excessive force being applied to the arm.

During the RMT phase, subjects had 30 minutes of intervention three times per week. The intervention involved the practice of three exercises appropriate to their needs, for 10 minutes each, and included exercises such as hand to mouth movements, reaching at table height and a reaching exercise to shoulder height. Feedback on the direction of the movement required and completion of the exercises was provided on screen through a series of target balls. In addition to visual feedback, haptic feedback was provided and was perceived by the subject as a feeling of increased resistance to movement when their hand strayed from the programmed movement pattern. The amount of assistance required by the subject is also programmed so that passive, active assisted or active movements can be completed.

The SS phase comprised sling suspension and involved the subject lying on their good side with their affected arm supported in an arm and forearm sling. Similar to the RMT they performed 3 exercises for 10 minutes each. Elbow flexion/extension with shoulder in neutral, shoulder flexion with elbow flexion and shoulder flexion with elbow extension. The minimum amount of assistance required to complete the movement was provided by the therapist and verbal cues were standardised.

\subsection{Outcome measurement}

Measures were taken in the same order at the start of every visit, which was at the same time every visit for each subject. The active range of motion of shoulder flexion was measured using the standardised positions as described by Norkin \& White ${ }^{35}$. The Fugl Meyer ${ }^{36}$ Assessment of Motor Recovery after Stroke was used to measure the impairment of the function of the arm and the Motor Assessment Scale ${ }^{37}$ measured limitations of arm activity. Since several background characteristics have been demonstrated to have an effect on the outcome of arm recovery, they were also measured. Sensation was measured using the Nottingham sensory assessment ${ }^{38}$, hemi neglect using the star cancellation test ${ }^{39}$, pain on visual analogue scale for those with no hemineglect and a verbal scale for those with abnormal star cancellation test score. The modified Ashworth scale ${ }^{40}$ was used to measure elbow tone at the start of the study and at the end of each phase. The investigator carried out both assessments and treatment. To decrease possible bias the scoring sheets were not totalled on the day of testing and were filed until the end of the study when they were then totalled and entered into an excel file.

\subsection{Data analysis}

Initially, the data from this trial was analysed visually, however due to the high variability between measures and difficulties in comparing the response of one participant to another a statistical method of analysis was sought. Several authors have suggested drawing lines through the data to assist visual analysis ${ }^{41,42}$, and using linear regression to statistically evaluate single case studies ${ }^{43,44}$ hence the general 
linear model was chosen to estimate a least squares line through each phase and the slope was considered as a measure of the rate of recovery. The model used allowed for an interaction effect between each participant and each time variable. In addition, it accounted for the fact that each participant started at a different baseline value and had a different rate of recovery for each phase.

A comparison of the fitted model to the raw data was completed; the continuity of the lines and the similarity of raw and predicted data demonstrated the appropriateness of the model and suggested that the slope values accurately represent the rate of recovery between phases. Examination of the residual plots for all variables was also satisfactory suggesting that the statistical model was a good fit of the data.

To analyse the change in Modified Ashworth scale score, the Wilcoxon Signed Rank test was used.

\section{Results}

The characteristics of the ten subjects in each group are included in tables 1 and 2. None of the participants reported any adverse effects from the treatment, except for subject 3 who reported an increase in shoulder pain following RMT, however her pain score at the end of the study was still less than that at baseline. It was hypothesised that this was due to the fact that she had a decrease in passive range of motion of external rotation and was working at the end of this range during treatment. Subject 2 missed 3 appointments during the SS phase, subject 13 missed one appointment during the SS phase, and subject 18 missed one treatment in each of the SS and RMT phases. All other participants completed all treatments and measurements. Some participants had ongoing physiotherapy once or twice a week, however none of them had a change in intervention or duration of HEP from baseline to RMT and SS phases.

Table 1 - Baseline characteristics of group 1

\begin{tabular}{|l|l|l|l|l|l|l|l|l|l|l|l|}
\hline Subject Number & $\mathbf{1}$ & $\mathbf{4}$ & $\mathbf{5}$ & $\mathbf{7}$ & $\mathbf{9}$ & $\mathbf{1 2}$ & $\mathbf{1 3}$ & $\mathbf{1 6}$ & $\mathbf{1 7}$ & $\mathbf{1 9}$ & Mean \\
\hline Gender & $\mathrm{M}$ & $\mathrm{F}$ & $\mathrm{F}$ & $\mathrm{M}$ & $\mathrm{M}$ & $\mathrm{M}$ & $\mathrm{M}$ & $\mathrm{M}$ & $\mathrm{M}$ & $\mathrm{F}$ & \\
\hline Affected side & $\mathrm{L}$ & $\mathrm{L}$ & $\mathrm{R}$ & $\mathrm{R}$ & $\mathrm{R}$ & $\mathrm{R}$ & $\mathrm{L}$ & $\mathrm{R}$ & $\mathrm{L}$ & $\mathrm{L}$ & \\
\hline Age at entry to study (years) & 71 & 70 & 79 & 66 & 63 & 62 & 52 & 64 & 59 & 74 & $\mathbf{6 6}$ \\
\hline Time since stroke (months) & 5 & 16 & 13 & 24 & 22 & 34 & 21 & 4 & 12 & 8 & $\mathbf{1 5 . 9}$ \\
\hline Fugl Meyer score /66 & 22 & 40 & 29 & 56 & 21 & 23 & 35 & 16 & 21 & 4 & $\mathbf{2 6 . 7}$ \\
\hline Nottingham sensory assessment /36 & 35 & 21 & 5 & 35 & 32 & 35 & 28 & 34 & 34 & 30 & $\mathbf{2 8 . 9}$ \\
\hline Star cancellation test /54 & 54 & 50 & 54 & 54 & 54 & 54 & 53 & 54 & 54 & 43 & $\mathbf{5 2 . 4}$ \\
\hline Wrist tone Modified Ashworth Scale 0-5 & 3 & 0 & 4 & 1 & 3 & 1 & 2 & 2 & 3 & 2 & $\mathbf{2 . 1}$ \\
\hline Hemianopia (0=absent, $\mathbf{1 = i n a t t e n t i o n )}$ & 0 & 0 & 0 & 0 & 0 & 0 & 1 & 0 & 0 & 0 & \\
\hline Visual analogue pain score 0-10 & 2 & 3.8 & 0 & 1.3 & 0.3 & 0 & 0 & 0 & 2.2 & 1.4 & $\mathbf{1 . 1}$ \\
\hline
\end{tabular}

(Table $1 \& 2$ here) 
Table 2 - Baseline characteristics of group 2

\begin{tabular}{|l|l|l|l|l|l|l|l|l|l|l|l|}
\hline Subject Number & 2 & $\mathbf{3}$ & $\mathbf{6}$ & $\mathbf{8}$ & $\mathbf{1 0}$ & $\mathbf{1 1}$ & $\mathbf{1 4}$ & $\mathbf{1 5}$ & $\mathbf{1 8}$ & $\mathbf{2 0}$ & $\mathbf{M e a n}$ \\
\hline Gender & $\mathrm{M}$ & $\mathrm{F}$ & $\mathrm{F}$ & $\mathrm{F}$ & $\mathrm{F}$ & $\mathrm{F}$ & $\mathrm{M}$ & $\mathrm{F}$ & $\mathrm{M}$ & $\mathrm{M}$ & \\
\hline Affected side & $\mathrm{R}$ & $\mathrm{R}$ & $\mathrm{L}$ & $\mathrm{L}$ & $\mathrm{L}$ & $\mathrm{R}$ & $\mathrm{R}$ & $\mathrm{L}$ & $\mathrm{L}$ & $\mathrm{L}$ & \\
\hline Age at entry to study (years) & 79 & 80 & 79 & 69 & 73 & 65 & 65 & 84 & 58 & 49 & $\mathbf{6 9 . 1}$ \\
\hline Time since stroke (months) & 3 & 19 & 60 & 39 & 10 & 25 & 3 & 3 & 19 & 75 & $\mathbf{2 8 . 1}$ \\
\hline Fugl Meyer score /66 & 57 & 46 & 48 & 31 & 4 & 12 & 39 & 31 & 15 & 21 & $\mathbf{2 7 . 4}$ \\
\hline Nottingham sensory assessment /36 & 35 & 36 & 33 & 32 & 33 & 24 & 34 & 18 & 17 & 35 & $\mathbf{2 9 . 1}$ \\
\hline Star cancellation test /54 & 54 & 53 & 52 & 54 & 54 & 52 & 54 & 44 & 49 & 54 & $\mathbf{5 1 . 8}$ \\
\hline Wrist tone Modified Ashworth Scale * $\mathbf{0 - 5}$ & 0 & 1 & 0 & 2 & 3 & 0 & 1 & 2 & 2 & 1 & $\mathbf{1 . 3}$ \\
\hline Hemianopia (0=absent, 1=inattention) & 0 & 0 & 0 & 0 & 0 & 0 & 0 & 1 & 1 & 0 & \\
\hline Visual analogue pain score 0-10 & 2.3 & 8.9 & 0 & 4.7 & 0 & 3.8 & 4.3 & 6 & 0 & 1.9 & $\mathbf{3 . 3}$ \\
\hline
\end{tabular}

The results of the slope values for the arm section of the Fugl-Meyer (FM-ARM) scale are presented in Table 3. Seven subjects had slope values in the RMT phase that were higher than both the baseline and SS phases. The maximum slope value in the RMT phase, seen in subject 1, suggests an increase of 10.62 points in the arm section of the Fugl-Meyer over the 9 RMT treatments. The mean difference between the baseline and RMT phases for group 1 was -0.25 (CI -0.52, 0.020, $\mathrm{p}=0.066$ ) suggesting a trend for a significantly higher slope in the RMT phase. The mean difference between baseline and RMT phases for group 2 was -0.056 (CI -0.406, 0.294, $\mathrm{p}=0.726$ ). The mean difference between RMT and SS phases for group 1 was 0.197 (CI $-0.055,0.449, \mathrm{p}=0.111$ ). The mean difference between SS and RMT phases for group 2 was -0.048 (CI $-0.25,0.154, \mathrm{p}=0.604)$.

Table 3 - Slope values for Fugl-Meyer Total Scores. Shaded values are where RMT slope is greater than both SS and baseline. 
Group 1

$\begin{array}{rrrrrrr}\text { Subject } & \text { Intercept } & \text { Baseline } & \text { RMT } & \text { SS } & \text { Subject } \\ \mathbf{1} & 26.76 & 0.57 & 1.18 & 0.61 & \mathbf{2} \\ \mathbf{4} & 43.30 & 0.23 & 0.38 & 0.27 & \mathbf{3} \\ \mathbf{5} & 33.82 & -0.15 & 0.76 & -0.18 & \mathbf{6} \\ 7 & 56.35 & 0.04 & 0.35 & 0.07 & \mathbf{8} \\ \mathbf{9} & 21.56 & 0.22 & 0.27 & -0.05 & \mathbf{1 0} \\ \mathbf{1 2} & 24.58 & -0.27 & 0.30 & 0.61 & \mathbf{1 1} \\ \mathbf{1 3} & 32.54 & 0.19 & 0.30 & 0.32 & \mathbf{1 4} \\ \mathbf{1 6} & 16.25 & 0.67 & 0.56 & 0.49 & \mathbf{1 5} \\ \mathbf{1 7} & 21.19 & 0.65 & 0.26 & 0.22 & \mathbf{1 8} \\ \mathbf{1 9} & 5.70 & -0.22 & 0.07 & 0.10 & \mathbf{2 0} \\ \text { Average } & & 0.19 & 0.44 & 0.25 & \text { Average }\end{array}$

\section{Group 2}

\begin{tabular}{|rrl|r|}
\hline Intercept & Baseline & SS & RMT \\
\hline 56.55 & 0.26 & 0.13 & 0.29 \\
\hline 47.41 & -0.21 & 0.76 & 0.27 \\
\hline 49.11 & 0.16 & 0.13 & 0.61 \\
\hline 32.70 & 0.35 & 0.45 & 0.45 \\
\hline 4.29 & -0.02 & 0.10 & 0.16 \\
\hline 11.47 & 0.75 & 0.26 & 0.22 \\
\hline 41.66 & 0.07 & 0.35 & 0.81 \\
\hline 31.22 & 0.60 & 0.81 & 0.74 \\
\hline 16.37 & 0.24 & 0.07 & 0.13 \\
\hline 19.49 & 1.10 & 0.32 & 0.18 \\
\hline & 0.33 & 0.34 & 0.39
\end{tabular}

(Table 3 here)

The results of the slope values for the total of the three arm sections of the Motor Assessment Scale are presented in table 4. Eight subjects had slope values in the RMT phase that were higher than both the baseline and SS phases. The maximum slope value in the RMT phase, seen in subject 5, suggests an increase of 4.41 points in the arm sections of the Motor Assessment Scale over the 9 RMT treatments.

The mean difference between the slopes of the baseline and RMT phases for group 1 was -0.114 (CI $-0.307,0.079, \mathrm{p}=0.215)$. The mean difference between slopes of the baseline and RMT phases for group 2 was -0.022 (CI $-0.158,0.1142, p=0.723$ ). 
The mean difference between slopes of the RMT and SS phases for group 1 was 0.039 (CI -0.111, 0.189, $\mathrm{p}=0.571$ ). The mean difference between slopes of the SS and RMT phases for group 2 was -0.143 (CI -0.2535, -0.0325, $\mathrm{p}=0.017$ ) suggesting a significantly higher mean slope in the RMT phase.

Table 4 - Slope values for Motor Assessment Scale Total scores. Shaded values are where RMT slope is greater than both SS and baseline.

Group 1

Subject

\section{4}

7.89

$\begin{array}{lr}\mathbf{5} & 4.58 \\ \mathbf{7} & 14.79\end{array}$

$9 \quad 1.25$

12

1.35

19

Average
3.99

1.99

0.80

0.00

13

16

17

0.00

$-0.01$

0.29

$0.01 \quad 0.25$

$0.02 \quad 0.16$

$0.02 \quad 0.10$

0.00

0.03

$0.00 \quad 0.00$

0.14

0.10

\section{Group 2}

Subject

2
3

Intercept

12.21

7.23

11.52

6.33

$-0.02$

10

11

1.16

3.17

4.12

1.87

2.51

\begin{tabular}{rl|r} 
Baseline & SS & RMT \\
0.29 & 0.06 & 0.20 \\
0.13 & 0.09 & 0.23 \\
0.22 & 0.02 & 0.27 \\
-0.06 & 0.03 & 0.31 \\
0.01 & 0.12 & -0.02 \\
& - & \\
0.13 & 0.03 & 0.01 \\
& - & \\
0.45 & 0.06 & 0.19 \\
0.22 & 0.05 & 0.39 \\
-0.11 & 0.14 & 0.08
\end{tabular}

$\begin{array}{ll}0.26 & 0.09\end{array}$

0.10

$\begin{array}{ll}0.15 & 0.03\end{array}$

(Table 4 here)

The results of the slope values for the active range of motion of shoulder flexion are presented in table 5. Twelve subjects had slope values in the RMT phase that were higher than both the baseline and SS phases. The maximum slope value in the RMT phase, seen in subject 5, suggests an increase of 6.93 degrees over the 9 RMT treatments.

The mean difference between the baseline and RMT phases for group 1 was 0.094 (CI $-0.38,0.192, \mathrm{p}=0.477$ ). The mean difference between slopes of the baseline and RMT phases for group 2 was -0.273 (CI $-0.597,0.051, p=0.089$ ). The mean difference between slopes of the RMT and SS phases for group 1 was 0.179 (CI $0.020,0.378, p=0.072$ ) suggesting a trend for a statistically higher slope in the RMT phase. The mean difference between slopes of the SS and RMT phases for group 2 
was $-0.188(\mathrm{CI}-0.4068,-0.0308, \mathrm{p}=0.084)$ suggesting a trend for a statistically higher mean slope in the RMT phase.

Table 5 - Slope values for active range of motion of shoulder flexion. Shaded values are where RMT slope is greater than both SS and baseline.

\section{Group 1}

Subject

$\begin{array}{rrrrr}\text { ject } & \text { Intercept } & \text { Baseline } & \text { RMT } & \text { SS } \\ \mathbf{1} & 5.01 & -0.07 & 0.43 & 0.26 \\ \mathbf{4} & 4.76 & -0.05 & 0.16 & 0.11 \\ \mathbf{5} & 5.83 & -0.24 & 0.13 & -0.03 \\ \mathbf{7} & 24.39 & 0.18 & 0.77 & -0.10 \\ \mathbf{9} & 0.07 & -0.02 & 0.12 & 0.03 \\ \mathbf{1 2} & 0.00 & 0.00 & 0.00 & 0.00 \\ \mathbf{1 3} & 14.65 & 1.18 & 0.39 & 0.17\end{array}$

$16-0.48$

$17 \quad 0.28$

$19 \quad 0.00$

Average

$\begin{array}{rrr}0.16 & 0.35 & -0.01 \\ 0.40 & 0.13 & 0.26 \\ 0.00 & 0.00 & 0.00 \\ 0.15 & 0.25 & 0.07\end{array}$

0.15
0.07

\section{Group}

2

\begin{tabular}{|rrrlr|} 
Subject & Intercept & Baseline & SS & RMT \\
$\mathbf{2}$ & 25.33 & -0.58 & 0.47 & 0.73 \\
$\mathbf{3}$ & 4.84 & 0.02 & 0.13 & 0.13 \\
$\mathbf{6}$ & 13.85 & 0.32 & 0.08 & 0.39 \\
$\mathbf{8}$ & 2.83 & 0.26 & 0.17 & 0.10 \\
$\mathbf{1 0}$ & 0.00 & 0.00 & 0.00 & 0.00 \\
$\mathbf{1 1}$ & 0.00 & 0.00 & 0.00 & 0.00 \\
$\mathbf{1 4}$ & 5.08 & -0.09 & - & 0.76 \\
& & & 0.22 & \\
$\mathbf{1 5}$ & 4.53 & 0.01 & 0.12 & 0.17 \\
$\mathbf{1 8}$ & -0.01 & 0.01 & 0.13 & 0.27 \\
$\mathbf{2 0}$ & 3.06 & 0.15 & 0.07 & 0.28 \\
\hline Average & & 0.01 & 0.10 & 0.28
\end{tabular}

(Table 5 here)

The change in score of the Modified Ashworth scale for the elbow in each phase is illustrated in table 6. The decrease in scores over the RMT phase is significant for group 1 and nearing significance for group 2.

Table 6 - Change in Modified Ashworth Scale score for the elbow in each phase

\begin{tabular}{|l|l|l|l|l|l|l|}
\hline & Group 1 & \multicolumn{5}{l|}{ Group 2 } \\
\hline & Baseline & RMT & SS & Baseline & RMT & SS \\
\hline $\begin{array}{l}\text { Decrease } \\
\text { score }\end{array}$ & 0 & 6 & 2 & 4 & 1 & 4 \\
\hline Increase score & 3 & 0 & 3 & 2 & 2 & 0 \\
\hline Equal scores & 7 & 4 & 5 & 4 & 7 & 6 \\
\hline Z value & -1.732 & -2.449 & -0.447 & -0.333 & -0.816 & -1.890 \\
\hline Significance & 0.083 & $\mathbf{0 . 0 1 4}$ & 0.655 & 0.739 & 0.414 & 0.059 \\
\hline
\end{tabular}

RMT=Robot mediated therapy 
$\mathrm{SS}=$ Sling Suspension

(Table 6 here)

\section{Discussion}

In order to evaluate whether the GENTLE/s system had a positive treatment effect, the rates of recovery between the baseline and RMT phases were compared. The average value for the slope was higher in the RMT than the baseline phase for all three outcome measures for both groups and for several subjects the slope of the SS phase was also greater than that in the baseline. Whilst not significant, the trends emerging from the results of this series of single case studies supports the literature that suggests that additional exercise based intervention involving repetition can produce positive treatment effects. This is consistent with the findings of metaanalyses $^{45,46}$, which suggest that higher intensities of rehabilitation result in improvements in activities of daily living. This result also concurs with the results of a systematic review of exercise therapy ${ }^{47}$, which also suggests that more intensive exercise therapy may be beneficial in improving outcome of the arm.

In seven subjects $(1,3,4,5,6,7$, and 9) the slope value was greater during the RMT phase than both the baseline and SS phases for all three outcome measures. All of these subjects shared the absence of hemianopia and a score greater than 20 on the Fugl Meyer Scale. Subjects 10, 11, 12, and 19, who had no active motion of shoulder flexion on entry to the study, did not demonstrate any clinically significant benefit from either SS or RMT. This supports the findings of studies that suggest that additional intervention is most beneficial for those with some movement initially ${ }^{48}$. Further research should consider whether adding robot mediated therapy early post stroke can improve outcome for those with little or no movement initially.

All three of the outcome variables for subject 17, and several other measures for other subjects, had the highest slope value during the baseline phase. As it is unlikely, given the time post stroke, that recovery was greater during these 3 weeks, it is possible that the rate of increase in scores could be due to a learning effect of the outcome measure, or due to some degree of unmasking of learned non-use in the affected arm.

Contrary to the belief that resisted exercise has a negative effect on tone, the GENTLE/s system had, for the majority of subjects, a positive effect on the tone of the affected elbow. Group 1 had a statistically significant decrease in tone over the RMT phase, while the scores for the majority of subjects in group 2 did not increase over the RMT phase.

Probably the most striking finding of this study was that no two subjects had the same response to the intervention. Both the magnitude of the differences in slopes and the outcome variables affected differed between individuals. This highlights the need for studies evaluating treatments for subjects with stroke to provide information about 
the subjects who have particularly good or bad responses to the intervention. It is this detail of information that is needed by clinicians when making decisions as to how best to treat that particular patient.

The comparison of the RMT and SS phase allows the specific components of the intervention responsible for the treatment effect to be evaluated. The treatments differ principally in the fact that SS involves single plane, non-functional movements with no visual feedback, whereas RMT involves the repeated practice of functional, meaningful, challenging movements with haptic and visual feedback. There were higher rates of recovery during the RMT than the SS phase on average for both groups for the active range of motion measure, and for subjects $1,2,3,4,5,6,7$, and 9 for all three measures, suggesting that adding visual feedback through virtual reality and the assistance of the robot can improve outcome. This concurs with the results of Plautz et $\mathrm{al}^{9}$ who found that cortical reorganisation in monkeys was optimised when the skill practiced was challenging and engaging. It is also supported by work by $\mathrm{Wu}$ et $\mathrm{al}^{49}$ who found that the kinematics of reaching with the affected arm improved when a meaningful object was present as opposed to reaching into space. It is also possible that the completion of virtual reality tasks, as opposed to single planar movements, increased attention, a factor that is important for motor learning post stroke $^{50}$. The common characteristics of these 7 patients who appeared to have a better response to RMT than SS is that they all had no hemianopia, a star cancellation test score greater than 50 and a Fugl-Meyer score of greater than 20 on admission to the study. They had varying levels of pain, sensation and tone and were at varying times post stroke, hand dominance was also not a factor.

The lack of statistical significance and variable results may be further explained by the variability of the data. Significant variability during the measurement only phase was found in all measures, especially in goniometry. The tester was an experienced senior clinician who was familiar with the outcome measures having used them both clinically and in a pilot study prior to this study and the reliability coefficients published for the measures suggested good test-retest reliability. However on plotting the data the variability was great and prohibited visual analysis. Further published data on reliability is required and for future studies the test-retest variability should be considered when choosing both the outcome measure and the criteria for clinically and statistically significant change.

Also, while the absolute values for the rate of recovery seem positive, the actual change in score on the outcome measures may not be clinically meaningful to either subjects or therapists. This may be because the actual dosage of the intervention, 4.5 hours over 3 weeks, is only a very small proportion of the subjects waking hours. Other studies $^{6,51,52}$ have delivered additional interventions of 900-1200 minutes and have reported a limited impact on impairment and function. It would appear from this literature that for additional intervention to have an impact, because of the nature of the arm deficit, the compliance of the participants and exercise delivered for in excess of 1200 minutes is required. Compliance was not an issue in this study and while the duration of GENTLE/s intervention represents the duration of treatment at most outpatient physiotherapy departments in Ireland, it would be interesting to evaluate the effect of the GENTLE/s system on arm function with a greater intensity and during the first three months post stroke when recovery is at its maximum. Increasing the intensity of the intervention may produce a change in activity limitations that is sufficient to influence participation. 


\section{Conclusion}

The trends emerging from the results of this series of single case studies support the literature that suggests that additional exercise based intervention involving repetition produces positive treatment effects. Treatment using the GENTLE/s RMT system may be preferable to one that simply involves repetitious exercises but further studies comparing it to additional conventional therapy are required. The differing response of the 20 subjects highlights the knowledge that subjects with stroke are inherently heterogeneous and that describing study subjects in terms of age and time post stroke is not sufficient. Multi-centre randomised controlled trials with large numbers of well described subjects and treatment and control groups with similar predictive factors for recovery are required to inform clinical practice and to increase the evidence base for RMT. The optimal duration of intervention with RMT is probably greater than that delivered in this study and research to investigate both the optimal dose and timing of intervention is required. While RMT has been developed in response to the output of both the clinical and neurophysiological literature, studies that combine treatment effects with mapping of change at brain level will most likely further knowledge of the mechanisms of recovery and guide physiotherapists in modifying treatments that optimally use this information.

Ultimately the goal of rehabilitation is to optimise recovery of the post stroke to enable the patient to return to their place in society and prevent decreased well being and quality of life. It is clear that an increase the amount of intervention that the arm receives is required and robotic technology is ideally placed to deliver additional exercise based intervention. The principles of robot mediated therapy are based on the output of the physiotherapy and neurophysiological research and the results of this study, and those of researchers in the United States and European, provides an increasing evidence base for this novel intervention.

\section{Clinical Message}

- During functional exercise post stroke, the haptic and visual feedback of a robotic system has a more positive treatment effect than single plane, repetitious exercises

- The results of this study suggest a positive treatment effect from robot mediated therapy systems and support the findings of other studies.

- Further research in the form of a randomised controlled trial is warranted

\section{Acknowledgements}

We are grateful to all our colleagues in the GENTLE/s consortium (University of Reading, UK; Rehab Robotics, UK; Zenon, Greece; Virgo, Greece; University of Staffordshire, UK; University of Ljubljana, Slovenia; Trinity College Dublin, Ireland; 
TNO-TPD, Netherlands; University of Newcastle, UK) for their ongoing commitment to this work. The work presented in this paper has been carried out with financial support from the Commission of the European Union, Framework 5, specific RTD programme 'Quality of Life and Management of Living Resources', QLK6-199902282, 'GENTLE/s - Robotic assistance in neuro and motor rehabilitation'. It does not necessarily reflect its views and in no way anticipates the Commission's future policy in this area.

\section{Competing interests}

There are none and the funding source had no influence over the analysis, interpretation and reporting of data.

\section{Contributors}

Dr Susan Coote designed the study and collected the data as part of her $\mathrm{PhD}$ thesis, she co-wrote the paper with Dr Emma Stokes, who was the PI for the project and PhD supervisor. Dr Brendan Murphy provided advice on statistical analysis. Dr William Harwin was project coordinator for GENTLE/s and provided feedback on the paper.

\section{References}

1. Wyller TB, Sveen U, Sodring KM, et al. Subjective well-being one year after stroke. Clin Rehabil 1997; 11: 139-144.

2. Pomeroy VM, Tallis RC. Physical therapy to improve movement performance and functional ability post stroke. Part 1. Existing evidence. Reviews Clinical Gerontology 2000;10:261-90.

3. Nudo RJ, Wise BM, SiFarmntes F, Miliken GW. Neural substrates for the effects of rehabilitative training on motor recovery after ischaemic infract. Science 1996; 272:1791-4

4. Plautz EJ, Miliken GW, Nudo RJ. Effects of repetitive motor training on movement representations in adult squirrel monkeys: role of use versus learning. Neurobiology of Learning and Memory 2000; 74 :27-55

5. Pomeroy VM, Tallis RC. Restoring movement and functional ability after stroke, now and the future. Physiotherapy 2002; 88: 3-17.

6. Ballinger C, Ashburn a, Low J, Roderick P. Unpacking the black box of therapy - a pilot study to describe occupational therapy and physiotherapy interventions for people with stroke. Clinical Rehabilitation 1999; 13:301-9.

7. Kwakkel G, Wagenaar RC, Twisk JW, Lankhorst GJ, Koetsier JC Intensity of leg and arm training after primary middle-cerebral-artery stroke: a randomised trial. Lancet 1999; 354(9174):191-6.

8. Butefisch C, Hummelsheim H, Denzler P, Mauritz KH (1995). Repetitive training of isolated movements improves the outcome of motor rehabilitation of the centrally paretic hand, Journal of Neurological Sciences 130: 59-68.

9. Burgar CG, Lum PS, Shor PC, et al. Development of robots for rehabilitation therapy: The Palo Alto VS/Stanford experience. Journal of Rehabilitation Research and Development 2000; 37: 663-673

10. Lum PS, Reinkensmeyer DJ, Lehman SL. Robotic assist devices for bimanual physical therapy: preliminary experiments. IEEE Trans Rehabil Eng 1993; 1 : 185-191.

11. Burgar CG, Lum PS, Shor M, et al. Rehabilitation of upper limb dysfunction in chronic hemiplegia: robot-assisted movement versus conventional therapy. Arch Phys Med Rehabil 1999; 80 :1121. 
12. Lum PS, Burgar CG, Kenney DE, et al. Quantification of force abnormalities during passive and active-assisted upper-limb reaching movements in poststroke hemiparesis. IEEE Trans Biomed Eng 1999; 46 : 652-662.

13. Shor PC, Lum PS, Burgar CG, et al. The effect of robot-aided therapy on arm joint passive range of motion. Integration of assistive technology in the information age. Proceedings Seventh International Conference on Rehabilitation Robotics. IOS Press Amsterdam, 2001:79-83.

14. Krebs HI, Volpe BT, Aisen M, et al. Increasing productivity and quality of care: robot-aided neuro-rehabilitation. Journal of Rehabilitation Research and Development 2000; 37 : 639-652

15. Krebs H, Hogan N, Aisen ML, et al. Robot-aided neurorehabilitation. IEEE Trans Rehabil Eng 1998; 6 :75-87.

16. Aisen ML, Krebs H, Hogan N, et al. The effect of robot- assisted therapy and rehabilitative training on motor recovery following stroke. Arch Neurol 1997; 54 : 443-446.

17. Volpe BT, Krebs HI, Hogan N, et al. A novel approach to stroke rehabilitation. Robot-aided sensorimotor stimulation. Neurology 2000; 54:1938-44.

18. Volpe BT, Krebs HI, Hogan N, et al. Robot training enhanced motor outcome in participants with stroke maintained over three years. Neurology 1999; 53:1874-76.

19. Finley MA, Fasoli SE, Dipietro L, Ohlhoff J, MacClellan L, Meister C, Whitall J, Macko R, Bever CT, Krebs HI, Hogan N (2005) Short-duration robotic therapy in stroke participants with severe upper-limb motor impairment. Journal of Rehabilitation Research \& Development 42(5): 683692.

20. MacClellan L, Bradham DD, Whitall J, Volpe B, Wilson PD, Ohlhoff J, Meister C, Hogan N, Krebs HI, Bever CT (2005) Robotic upper-limb neurorehabilitation in chronic stroke participants 42(6):717-722.

21. Fasoli SE, Krebs HI, Stein J, Frontera W, Hogan N (2003) Effects of robotic therapy on motor impairment and recovery in chronic stroke. Arch Phys Med Rehabil 84: 477-82.

22. Fasoli SE, Krebs HI, Stein J, Frontera WR, Hughes R, Hogan N (2004) Robotic therapy for chronic motor impairments after stroke: follow-up results. Arch Phys Med Rehabil 85: 1106-11.

23. Stein J, Krebs HI, Fasoli SE, Hughes R, Hogan N (2004) Comparison of two techniqarms of robot-aided upper limb exercise training after stroke. Am J Phys Med Rehabil 83(9): 720728.

24. Ferraro M, Palazzolo JJ, Krol J, Krebs HI, Hogan N, Volpe BT (2003) Robotaided sensorimotor arm training improves outcome in participants with chronic stroke. Neurology 61: 1604-07.

25. Reinkensmeyer DJ, Kahn LE, Averbuch M, et al. Understanding and treating arm movement after chronic brain injury: progress with the ARM Guide. Journal of Rehabilitation Research and Development 2000; 37: 653-62.

26. Reinkensmeyer DJ, Schmidt BD, Rymer WZ. Mechatronic assessment of arm impairment after chronic brain injury. Technology and Health Care 1999; 7:431-35.

27. Reinkensmeyer DJ, Dewald JPA, Rymer WZ. Guidance-based quantification or arm impairment following brain injury: a pilot study. IEEE Trans Rehabil Eng 1999; 7:1-11. 
28. Kahn LE, Averbuch M, Rymer WZ, et al. Effect of robot-assisted and unassisted exercise on functional reaching in chronic hemiparesis. Proceedings $23^{\text {rd }}$ Annual IEEE Engineering in Medicine and Biology Conference, Istanbul, Turkey, October 25-28.

29. Fasoli SE, Krebs HI, Hogan N (2005) Rehabilition robotics for the paretic arm after stroke: an efficacy review. Arch Phys Med Rehabil 86: E9.

30. www.http://reharob.manuf.bme.hu Accessed 17.01.2006

31. Hesse S, Schmidt, H, Werner C (2006) Machines to support motor rehabilitation after stroke: 10 years of experience in Berlin. Journal of Rehabilitation Research and Development 43(5):671-678

32. http://www.gentle.reading.ac.uk/ Accessed 17.01.2006

33. Coote S, Stokes EK. Effect of robot-mediated therapy on arm dysfunction post-stroke-a single case study, Physiotherapy, 2005; 91: 250-256

34. Katzman R, Brown T, Fuld P, Peck A, Schechter R, Schimmel H Validation of a short orientation-memory-concentration test of cognitive impairment. American Journal Psychiatry 1983;140:734-9

35. Norkin C, White DJ. Measurement of joint motion, a guide to goniometry. Philadelphia : FA Davis Company, 1995

36. Fugl-Meyer AR, Jaaslo L, Leyman et al 1975 The post stroke hemiplegic patient 1. A method for evaluation of physical performance. Scandinavian Journal of Rehabilitation Medicine 7:13-31

37. Carr JH, Shepherd RB, Nordholm L et al 1985 Investigation of a new motor scale for stroke patients. Physical Therapy 65:175-80

38. Lincoln NB, Jackson JM, Adams SA. Reliability and revision of the Nottingham sensory assessment for stroke patients. Physiotherapy; 1998; 84(8):358-65

39. Wilson B, Cockburn J, Halligan PW. Behavioural inattention test. Titchfield, Thames Valley Test Company. 1987

40. Pandyan AD, Johnson GR, Price CIM, et al. A review of the properties and limitations of the Ashworth and modified Ashworth scales as measures of spasticity. Clinical Rehabilitation 1999;13:373-83

41. Kazdin AE Single case research designs. Oxford University Press. 1982

42. Zhan S, Ottenbacher KJ. Single subject research designs for disability research. Disability and Rehabilitation 2001; 23(1):1-8

43. Backman CL, Harris SR, Chisholm J-AM, Monette AD. Single-subject research in rehabilitation: a review of studies using $\mathrm{AB}$, withdrawal, multiple baseline and alternating treatment designs. Archives Physical Medicine Rehabilitation 1997;78:1145-53

44. Brobovitz CD, Ottenbacher KJ. Comparison of visual inspection and statistical analysis of single-subject data in rehabilitation research. Archives Physical Medicine Rehabilitation 1998;77:94-102

45. Kwakkel G, Wagenaar RC, Koelman TW, et al. Effects of Intensity of Rehabilitation after Stroke. A research synthesis. Stroke 1997;28:1550-6

46. Langhorne P, Wagenaar R, Partridge C. Physiotherapy after stroke: more is better? Physiotherapy Research International 1996;1(2):75-83

47. Van der Lee JH, Snels IAK, Beckerman H, et al. Exercise therapy for arm function in stroke patients: a systematic review of randomised controlled trials. Clinical Rehabilitation 2001;15:20-31 
48. Parry RH, Lincoln NB, Vaas CD (1999) Effect of severity of arm impairment on response to additional physiotherapy early after stroke. Clinical Rehabilitation 13(3):187-98

49. Wu C, Trombly C, Lin K, Tickle-Degnen L. A kinematic study of contextual effects on reaching performance in persons with and without stroke: inflarmnce of object availability. Archives Physical Medicine Rehabilitation 2000;81:95-101

50. Robertson IH, Ridgeway V, Greenfield E, Parr A. Motor recovery after stroke depends on intact sustained attention: a 2-year follow up study. Neuropsychology 1997;1(2):290-5

51. Blennerhassett J, Dite W. Additional task-related practise improves mobility and upper limb function early after stroke: A randomised controlled trial. Aust J of Physiother 2004; 50: 219-224.

52. Sunderland A, Tinson DJ, Bradley EL, Fletcher D, Langton-Hewer R, Wade DT. Enhanced physical therapy improves recovery of arm function after stroke. A randomised controlled trial. J Neurol Neurosurg Psychiatry 1992; 55: 530-535. 